J. Lake Sci. (湖泊科学), 2014, 26(6): 844-852

http: //www. jlakes.org. E-mail : jlakes@niglas.ac.cn

(C) 2014 by Journal of Lake Sciences

\title{
三峡大坝运行前后西洞庭湖鱼类群落结构特征变化"
}

\author{
朱 轶 ${ }^{1}$, 吕 偲 ${ }^{1}$, 胡慧建 ${ }^{2}$, 王忠锁 ${ }^{3}$, 贾亦飞 $^{1}$, 何木盈 ${ }^{4}$, 黄小军 ${ }^{4}$, 雷光春 ${ }^{1 * *}$ \\ (1: 北京林业大学自然保护区学院,北京 100083) \\ (2: 华南濒危动物研究所,广州 510260$)$ \\ (3: 首都师范大学生命科学学院, 北京 100048$)$ \\ (4:西洞庭湖国家级自然保护区, 常德 415900)
}

\begin{abstract}
摘 要: 鱼类是湿地生态系统中重要的组成部分, 鱼类的群落结构动态直接反映湿地生境及外部驱动力的变化. 三峡大 坝运行后, 长江中游江湖水文情势发生了变化, 西洞庭湖地处洞庭湖西部, 是受此变化影响最为直接的区域之一. 为监测 西洞庭湖鱼类群落结构变化特征,分析其变化原因,于 2002 年 9 月-2003 年 8 月和 2012 年 7 月- 2014 年 1 月,在西洞庭 湖进行了两次鱼类群落调查. 共鉴定到鱼类 7 目 17 科 91 种, 其中鲤形目最多, 为 58 种, 占总种数的 $63.7 \%$. 两次调查结 果显示, 三峡大坝运行后西洞庭湖鱼类物种数由 85 种下降到 66 种, Shannon-Wiener 多样性指数和 Pielou 均匀度指数分别 由 5.00 和 1.11 下降为 4.14 和 1.00 , 鱼类个体小型化趋势明显. 两次调查物种数和个体数量最多的类群均为底层、定居 性、杂食性鱼类, 且其比例有增加的趋势, 而肉食性鱼类、中上层鱼类、半洄游性鱼类和产粘性卵、沉性卵鱼类个体数量占 比均有减小的趋势,其中中上层鱼类变化有显著性差异. 三峡大坝运行后 10 年间,西洞庭湖鱼类多样性呈现下降趋势. 研究表明,西洞庭湖鱼类生境丧失、捕捞胁迫,加剧了一些特定类群的生存压力,并反映于鱼类群落结构的变化.
\end{abstract}

关键词: 西洞庭湖;鱼类;群落结构;三峡大坝;生境丧失;过度捕捞

\section{Changes in fish community structure in West Dongting Lake after the operation of the Three Gorges Dam}

ZHU Yi ${ }^{1}$, LÜ $\mathrm{Cai}^{1}$, HU Huijian ${ }^{2}$, WANG Zhongsuo ${ }^{3}$, JIA Yifei ${ }^{1}$, HE Muying ${ }^{4}$, HUANG Xiaojun ${ }^{4} \&$ LEI Guangchun ${ }^{1}$

( 1 : School of Nature Conservation, Beijing Forestry University, Beijing 100083, P. R. China)

(2: South China Institute of Endangered Animals, Guangzhou 510260, P. R. China)

(3:School of Life Sciences, Capital Normal University, Beijing 100048, P. R. China)

(4: West Dongting Lake National Nature Reserve, Changde 415900, P. R. China)

Abstract: Fishes, as one of the important components of wetland ecosystem, have been used as the indicator of the wetland ecosystem health. Investigation on its assemblages changes may reflect the drivers of change in the wetlands. After the operation of the Three Gorges Dam, the hydrological regime between the Yangtze River and the lakes in mid-Yangtze River basin has been changed. West Dongting Lake has been directly impacted by the operation of the Three Gorges Dam due to its close hydrological connections with the Yangtze River. To monitor the changes of fish community structure at West Dongting Lake and analyze the causes of the changes, we conducted two surveys, of which the first one was before the operation of Three Gorges Dam, from September 2002 to August 2003; and the second one was after the operation of Three Gorges Dam, from July 2012 to February 2014. In total, 91 fish species were identified, which belong to 7 orders and 17 families. The most specie-rich order was Cypriniformes ( 58 species), accounting for $63.7 \%$ of all species identified. According to the survey results, the number of fish species at West Dongting Lake declined from 85 to 66 ; the diversity index of Shannon-Wiener declined from 5.00 to 1.11 , while the evenness in-

* 国家重点基础研究发展计划“973”项目 (2012CB417005)资助. 2014-03-10 收稿;2014-04-03 收修改稿. 朱轶 (1986 ), 男,硕士研究生;E-mail: zhuyi198602@ 163.com.

** 通信作者;E-mail: guangchun8099@ gmail.com. 
dex of Pielou declined from 4. 14 to 1.00. Body size of all fishes became smaller after the operation of the Three Gorges Dam. The structure of fish communities were also changed both in the dominant species and assemblages composition. The dominant fish groups include bottom feeders, settling fishes and omnivorous fishes, and its proportions in the assemblages have been increasing. We observed decline in the proportions of carnivorous fishes, pelagic fishes, semi-migratory fishes, and fishes that laying adhesive egg, as well as demersal eggs, among which, pelagic fishes declined significantly. The species diversity in West Dongting Lake declined after the operation of Three Gorges Dam. Our results reveal that habitat loss and over fishing are major threats to the survival of some specific fish groups and have been reflected in the changes of the fish community structure.

Keywords: West Dongting Lake; fish; community structure; Three Gorges Dam; habitat loss; overfish

群落生态学是现代生态学理论中极为重要的部分. 群落和其他非生物因子通过物质循环和能量流动构 成特定功能的生态系统 ${ }^{[1]}$. 生物群落层次上的研究, 能够充分了解各个种群和环境之间的相互联系与影响, 进而揭示生态系统功能的响应过程 ${ }^{[2]}$. 由于鱼类位于湿地生态系统的食物链顶端, 其群落结构对环境的变 化有着非常敏感的响应 ${ }^{[3]}$, 因此开展长期持续的鱼类监测, 研究鱼类群落结构的变化, 对了解湿地生态系统 对环境变化的响应过程具有重要意义.

洞庭湖位于长江中游, 是长江仅有的两个大型通江湖泊之一, 其水位涨落变幅大, 丰枯季节水位落差可 达 $10 \mathrm{~m}$ 以上,独特的水文波动特征造就了多样的栖息地类型,为鱼类提供了广阔的育肥场和产卵场 ${ }^{[4]}$. 自 1977 年有比较系统的洞庭湖鱼类历史记录的 30 多年间, 调查记录到的鱼类物种数一直在 $104 \sim 119$ 种之 间,但 2008 年以来, 记录到的洞庭湖鱼类种数骤降到 $69 \sim 85$ 种之间, 过度捕拹、水质污染和大坝阻隔被认为 是导致洞庭湖鱼类多样性下降的主要原因 ${ }^{[5-11]}$.

随着清洁能源的推广, 水力发电得到了极大的发展, 大坝对于其周围环境的影响也日益加深 ${ }^{[12]}$. 大坝 的阻隔作用以及流量调节效应,改变了鱼类长期适应的栖息地,使得鱼类群落结构发生相应变化 ${ }^{[13-16]} .1981$

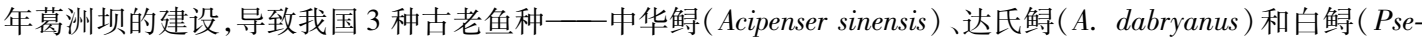
phurus gladius) 种群数量急速下降 ${ }^{[17]}$, 同样, 大坝还威胁着一些其他土著鱼种的生存空间 ${ }^{[18]}$. Gehrke 等对比 澳大利亚 Tallowa 大坝建设前后 20 年的鱼类群落组成发现, 大坝建成后鱼类多样性减少, 上下游鱼类群落结 构也有了明显的分化 ${ }^{[19]}$. 自 2003 年三峡大坝运行以来,洞庭湖的水文情势、江湖水体交换以及景观格局均 发生了较为明显的变化 ${ }^{[20-22]}$. 为了解鱼类群落对于环境变化的响应, 本研究选择洞庭湖水文过程最为复杂 的西洞庭湖为研究区域,通过 2002 年 9 月- 2003 年 8 月和 2012 年 7 月- 2014 年 1 月两次鱼类调查,分析西 洞庭湖鱼类群落结构变化特征, 探讨鱼类群落结构变化的原因并提出相应的保护建议.

\section{1 研究区域与方法}

\section{1 研究区域}

西洞庭湖位于湖南省汉寿县, 地处洞庭湖西部, 承接松滋、虎渡、藕池三口和沅、澧两水五支人流, 主湖 区目平湖位于赤山岛西侧, 是洞庭湖水文过程最为复杂的区域 (图 1 ).

\section{2 调查方法}

2002 年 $9-12$ 月、2003 年 1-3 月、2003 年 7-8 月,在西洞庭湖逐月进行鱼类群落调查, 每次调查持续 $10 \sim 15 \mathrm{~d} ; 2012$ 年 7 月、2013 年 3 月和 2014 年 1 月,在西洞庭湖进行了 3 次鱼类群落调查, 每次调查持续 $10 \sim 15$ d. 调查时间在禁渔期之外, 涵盖了西洞庭湖丰枯水季.

调查地点的选取: 1 ) 河流人湖口, 包括长江三口人湖口 (南嘴)、澧水人湖口 (柳林嘴) 和沅江人湖口 ( 接 港）;2) 湖泊中不同生境代表样点,包括“冬季为洲,夏季为湖” 的浅水湖区 (半边湖、打靶台、蒋家嘴等) 以及 四季为水的深水湖区 (河道).

调查方式以现场跟踪渔民作业 (跟船、定置网) 的渔获物调查为主. 现场对渔船作业渔获物进行种类鉴 别, 分别统计各类鱼类尾数,对现场无法鉴定的鱼种用 $95 \%$ 酒精保存,带回实验室进一步鉴定、分析. 同时 结合码头渔获物调查,仅累积统计该月出现的物种数. 物种鉴定主要参考《中国动物志》 ${ }^{[23-26]}$.

该区域渔民作业工具有:丝(挂)网、地笼、迷魂阵、(电)拖网、手抄网、布网和流刺网等. 两次调查尽量 保证所使用网具的强度一致,调查时间、地点、方法覆盖了不同季节、生境、取样方式,尽可能保证获取数据 


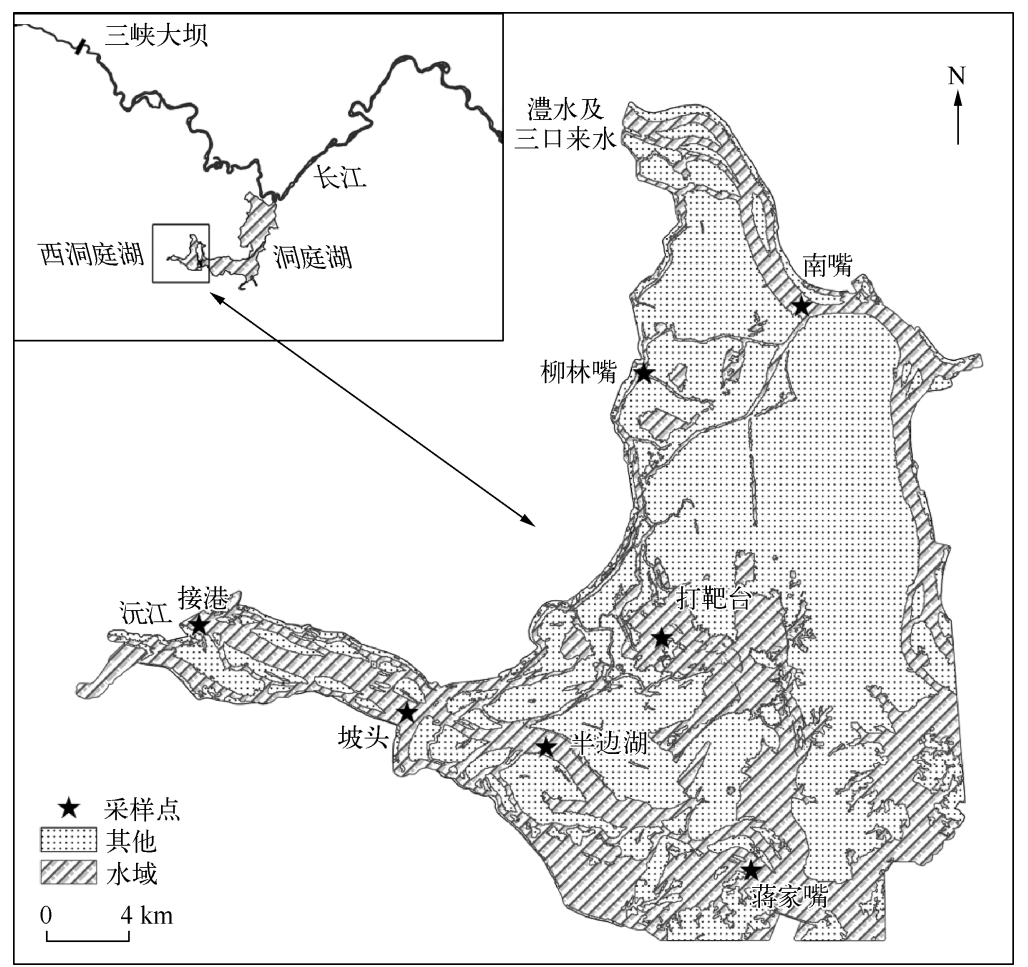

图 1 西洞庭湖位置及采样点

Fig. 1 Location of West Dongting Lake and sampling sites

的完整性.

\section{3 数据统计方法}

1.3.1 数据可比性 采用 “抽样数量一累积种数对数曲线” 检验数据的可比性.

1.3.2 数据检验 针对每种生态类群, 选择不同种类的鱼类尾数占整体渔获物的比例, 对两次调查结果进行 卡方检验.

1.3.3 多样性指数 相对多度 ${ }^{[1]}: R A=P_{i} \times 100 \%$; Shannon-Wiener 多样性指数 ${ }^{[6]}: H^{\prime}=-\sum P_{i} \log _{2} P_{i}$; Pielou 均匀度指数 ${ }^{[6]}: J=H^{\prime} / \ln S$. 式中, $P_{i}$ 为第 $i$ 种的个体数占群落中总个体数的比例, $S$ 为系统中的物种数.

\section{4 分类方法}

按照鱼类的生活习性和特征, 将西洞庭湖鱼类划分为 4 个生态类型 $\left.{ }^{[27]}: 1\right)$ 按照鱼类食性, 将西洞庭湖鱼 类划分为肉食性、杂食性、植食性 3 个类群. 捕食鱼虾为主的类群, 为肉食性鱼类; 既取食动物性饵料, 又取 食植物性㙁料的类群, 为杂食性鱼类; 主要以水草、藻类、植物碎屑为食的类群, 为植食性鱼类;2) 按照鱼类 栖息喜好的垂直水层, 将西洞庭湖鱼类划分为中上层、中下层、底层鱼类 3 个类群; 3 ) 按照鱼类洄游习性,将 西洞庭湖鱼类划分为洄游性、半洄游性、定居性 3 个类群. 生长和繁殖分别在江河和海洋中完成的, 为洄游 性鱼类; 以“四大家鱼” 等为代表的, 在湖泊中生长育肥, 生殖季节洄游至江河中繁殖的类群, 为半洄游性鱼 类; 生长和繁殖均在在山溪、河流或湖泊中进行的类群, 为定居性鱼类; 4) 按照鱼类产卵的类型, 将西洞庭湖 鱼类划分为漂流性卵、粘性卵、沉性卵 3 个类群. 产漂流性卵鱼类主要是指卵的密度小于水的密度, 产卵需 要流水环境, 卵随水漂流发育的类群; 产粘性卵鱼类主要为卵具粘性, 产卵主要在浅水区域, 卵粘附在靠近 水面的植物、石块等介质上发育的类群; 产沉性卵类群主要指卵的密度大于水的密度或者卵具粘性, 沉于水 底孵化的类群, 如鱊属 (Acheilognathus) 和黄滪鱼属 (Pelteobagrus) 等, 主要产卵介质为湖底的贝壳和坑穴, 依 此也都划分为产沉性卵类群. 


\section{2 结果与分析}

\section{1 鱼类物种组成}

两次调查共抽取样品 38161 尾, 鉴定到鱼 类 91 种,隶属于 7 目 17 科 60 属. 其中,鲤形目 鱼类种数最多,为 58 种,占总种数的 $63.7 \%$; 其 次为鲇形目, 14 种, 占总种数的 $15.4 \%$; 鲇形 目, 12 种,占总种数的 $13.2 \%$. 图 2 为两次调查 抽样数量和累积物种数的对数曲线, 结果表明 两次鱼类调查的样本量可以用于数据的比较分 析. 两次调查物种数最多的科、目均为鲤形目 鲤科和鲇形目魭科, $2012-2013$ 年调查物种数 为 66 种, 少于 $2002-2003$ 年物种数 (85 种) (附表 I ).

\section{2 生物多样性指数}

生物多样性一般用物种丰富度和分布的均 匀程度作为参照 ${ }^{[28]}$, 本文选取 Shannon-Wiener 多样性指数和 Pielou 均匀度指数对西洞庭湖鱼 类多样性进行分析. 两次调查对比,西洞庭湖 鱼类 Shannon-Wiener 多样性指数和 Pielou 均匀 度指数分别由 $2002-2003$ 年的 $5.00 、 1.11$ 下

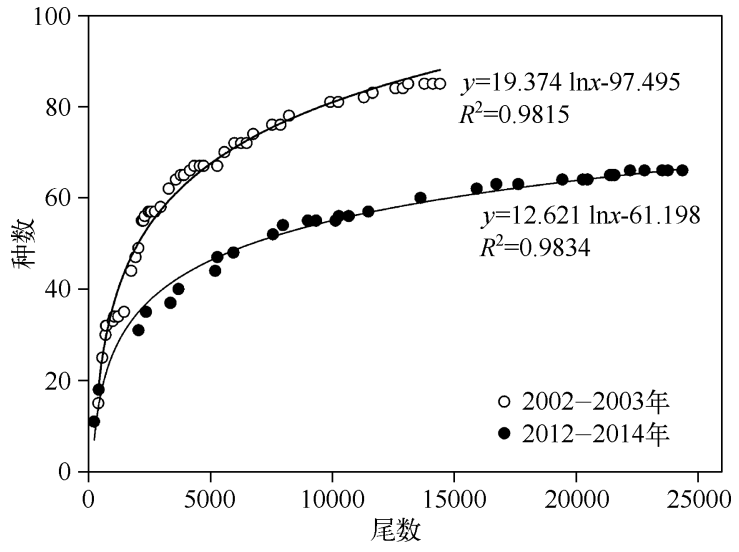

图 2 两次调查西洞庭湖渔获物 抽样数量一累积物种数对数曲线

Fig. 2 Logarithmic curve about individuals of sampling and species number of the two investigations in West Dongting Lake 降到 2012-2014 年的 4.14、1.00.

\section{3 群落结构变化}

2.3.1 优势种变化 两次调查中,渔获物中相对多度前 10 位的鱼类组成 (表 1) 物种有所变化. 2002-2003 年,鲫、贝氏銫相对多度均超过 10\%,为优势物种;2012-2014 年蛇鮈相对多度超过鲫,成为第一优势种. 两 次调查的共性特征表现为除鲤外,优势经济鱼类均以小型定居性的鲫、黄滪鱼和䁤属等为主.

表 1 三峡大坝运行前后西洞庭湖鱼类相对多度及其生态类型 *

Tab. 1 Relative abundance and eco-type of fish in West Dongting Lake before and after the operation of the Three Gorges Dam

\begin{tabular}{|c|c|c|c|c|c|}
\hline $2002-2003$ 年 & 尾数 & 相对多度 & 2012-2014 年 & 尾数 & 相对多度 \\
\hline 鲫 $(O 、 D 、 S 、 V)$ & 1989 & $13.80 \%$ & 蛇鮈 $(\mathrm{O} 、 \mathrm{D} 、 \mathrm{~S} 、 \mathrm{SE})$ & 4714 & $19.85 \%$ \\
\hline 贝氏銫 $(\mathrm{O} 、 \mathrm{U} 、 \mathrm{~S} 、 \mathrm{SE})$ & 1502 & $10.42 \%$ & 鲫 $(O 、 D 、 S 、 V)$ & 2860 & $12.04 \%$ \\
\hline 兴凯鱊( O、L、S、DE) & 996 & $6.91 \%$ & 兴凯鱊( O、L、S、DE) & 2839 & $11.95 \%$ \\
\hline 麦穗鱼 $(O 、 U 、 S 、 D E)$ & 803 & $5.67 \%$ & 光泽黄颡鱼 $(O 、 D 、 S 、 D E)$ & 1635 & $6.88 \%$ \\
\hline 鲤 $(O 、 D 、 S 、 V)$ & 658 & $4.67 \%$ & 银鮈 $(O 、 L 、 S 、 S E)$ & 1581 & $6.66 \%$ \\
\hline 普栉鰕虎鱼 $(C 、 D 、 S 、 D E)$ & 652 & $4.53 \%$ & 光唇蛇鮈 $(O 、 D 、 S 、 S E)$ & 1342 & $5.65 \%$ \\
\hline 大鳍鱊 $(\mathrm{O} 、 \mathrm{~L} 、 \mathrm{~S} 、 \mathrm{DE})$ & 533 & $3.70 \%$ & 鲤 $(O 、 D 、 S 、 V)$ & 1297 & $5.46 \%$ \\
\hline 似鳊 $(\mathrm{O} 、 \mathrm{~L} 、 \mathrm{~S} 、 \mathrm{SE})$ & 498 & $3.56 \%$ & 大鳍鱊 $(\mathrm{O} 、 \mathrm{~L} 、 \mathrm{~S} 、 \mathrm{DE})$ & 1063 & $4.48 \%$ \\
\hline 太湖新银鱼 $(C 、 U 、 S 、 D E)$ & 460 & $3.20 \%$ & 似鳊 $(\mathrm{O} 、 \mathrm{~L} 、 \mathrm{~S} 、 \mathrm{SE})$ & 1032 & $4.35 \%$ \\
\hline 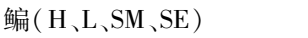 & 436 & $3.03 \%$ & 黄颡鱼 $(\mathrm{O} 、 \mathrm{D} 、 \mathrm{~S} 、 \mathrm{DE})$ & 686 & $2.89 \%$ \\
\hline
\end{tabular}

$* \mathrm{C}$ : 肉食性; $\mathrm{O}$ : 杂食性; $\mathrm{H}$ : 植食性; $\mathrm{D}$ : 底层; $\mathrm{U}$ : 中上层 $; \mathrm{L}$ : 中下层 $; \mathrm{SM}$ : 半洄游性 $; \mathrm{S}$ : 定居性; $\mathrm{M}$ 洄游性; $\mathrm{SE}$ : 漂流性卵; $\mathrm{V}$ : 粘性卵; DE: 沉性卵.

2.3 .2 生态类群变化 对同一生态类群的鱼类群落, 我们选择用每一种鱼类尾数所占整体的比例为一个样 本, 对三峡大坝运行前后的两次调查结果进行了卡方检验, 仅中上层鱼类的两次调查结果有显著差异 $\left(\chi^{2}=\right.$ 
$8.9069, P<0.005)$.

1) 不同食性物种变化:两次调查中,西洞庭湖最多的类群均为杂食性鱼类,肉食性鱼类减少最多 (12 种), 尾数占比减少了 $15.0 \%$,植食性鱼类变化不大 (表 2).

表 2 三峡大坝运行前后西洞庭湖不同食性鱼类物种变化

Tab. 2 Variation of fish composition in diet in West Dongting Lake before and after the operation of the Three Gorges Dam

\begin{tabular}{|c|c|c|c|c|c|c|c|c|c|c|c|c|}
\hline \multirow{2}{*}{ 年份 } & \multicolumn{4}{|c|}{ 肉食性 } & \multicolumn{4}{|c|}{ 杂食性 } & \multicolumn{4}{|c|}{ 植食性 } \\
\hline & 种数 & 占比 & 尾数 & 占比 & 种数 & 占比 & 尾数 & 占比 & 种数 & 占比 & 尾数 & 占比 \\
\hline $2002-2003$ 年 & 39 & $45.9 \%$ & 3180 & $22.0 \%$ & 39 & $45.9 \%$ & 10244 & $70.9 \%$ & 7 & $8.2 \%$ & 1023 & $7.1 \%$ \\
\hline $2012-2014$ 年 & 27 & $40.9 \%$ & 1652 & $7.0 \%$ & 33 & $50.0 \%$ & 20946 & $88.2 \%$ & 6 & $9.1 \%$ & 1153 & $4.8 \%$ \\
\hline
\end{tabular}

2 ) 不同栖息水层物种变化:两次调查对比表明,西洞庭湖中上层鱼类减少最多 (8 种), 尾数占比减少 $28.6 \%$, 底层鱼类增加最多, 尾数占比增加 $21.4 \%$, 鱼类群落有从均匀分布向底层类群集中的趋势 (表 3 ).

表 3 三峡大坝运行前后西洞庭湖不同栖息水层鱼类物种变化

Tab. 3 Variation of fish composition in vertical space distribution in West Dongting Lake before and after the operation of the Three Gorges Dam

\begin{tabular}{|c|c|c|c|c|c|c|c|c|c|c|c|c|}
\hline \multirow{2}{*}{ 年份 } & \multicolumn{4}{|c|}{ 中上层 } & \multicolumn{4}{|c|}{ 中下层 } & \multicolumn{4}{|c|}{ 底层 } \\
\hline & 种数 & 占比 & 尾数 & 占比 & 种数 & 占比 & 尾数 & 占比 & 种数 & 占比 & 尾数 & 占比 \\
\hline $2002-2003$ 年 & 26 & $30.6 \%$ & 4778 & $33.1 \%$ & 26 & $30.9 \%$ & 4093 & $28.3 \%$ & 33 & $38.8 \%$ & 5576 & $38.6 \%$ \\
\hline 2012-2014 年 & 18 & $27.3 \%$ & 1057 & $4.5 \%$ & 21 & $31.8 \%$ & 8449 & $35.5 \%$ & 27 & $40.9 \%$ & 1425 & $60.0 \%$ \\
\hline
\end{tabular}

3 ) 不同洄游习性物种变化:两次调查结果显示西洞庭湖鱼类均以定居性为主, 洄游性鱼类和半洄游性 鱼类在渔获物中占比均很小,在 2012-2014 年调查中未发现洄游性鱼类 (表 4).

表 4 三峡大坝运行前后西洞庭湖不同洄游习性鱼类物种变化

Tab. 4 Variation of fish species in different migration patterns in West Dongting Lake before and after the operation of the Three Gorges Dam

\begin{tabular}{|c|c|c|c|c|c|c|c|c|c|c|c|c|}
\hline \multirow{2}{*}{ 年份 } & \multicolumn{4}{|c|}{ 洄游性 } & \multicolumn{4}{|c|}{ 半洄游性 } & \multicolumn{4}{|c|}{ 定居性 } \\
\hline & 种数 & 占比 & 尾数 & 占比 & 种数 & 占比 & 尾数 & 占比 & 种数 & 占比 & 尾数 & 占比 \\
\hline $2002-2003$ 年 & 2 & $2.4 \%$ & 46 & $0.3 \%$ & 11 & $12.9 \%$ & 774 & $5.4 \%$ & 70 & $84.7 \%$ & 13627 & $94.3 \%$ \\
\hline $2012-2014$ 年 & 0 & 0 & 0 & 0 & 9 & $13.6 \%$ & 385 & $1.6 \%$ & 57 & $86.4 \%$ & 23366 & $98.4 \%$ \\
\hline
\end{tabular}

4 ) 不同产卵习性物种变化:两次调查不同产卵习性鱼类物种变化幅度不大,产粘性卵和沉性卵的鱼类 尾数占比均有减少的趋势, 而产漂流性卵鱼类尾数占比增加, 成为渔获物种占比最高的类群 (表 5 ).

表 5 三峡大坝运行前后西洞庭湖不同产卵习性鱼类物种变化

Tab. 5 Variation of fish species in spawning habit in West Dongting Lake

before and after the operation of the Three Gorges Dam

\begin{tabular}{|c|c|c|c|c|c|c|c|c|c|c|c|c|}
\hline \multirow{2}{*}{ 年份 } & \multicolumn{4}{|c|}{ 漂流性卵 } & \multicolumn{4}{|c|}{ 粘性卵 } & \multicolumn{4}{|c|}{ 沉性卵 } \\
\hline & 种数 & 占比 & 尾数 & 占比 & 种数 & 占比 & 尾数 & 占比 & 种数 & 占比 & 尾数 & 占比 \\
\hline $2002-2003$ 年 & 28 & $33.0 \%$ & 4222 & $29.2 \%$ & 33 & $38.8 \%$ & 4679 & $32.4 \%$ & 24 & $28.2 \%$ & 5546 & $38.4 \%$ \\
\hline 2012－2014 年 & 21 & $31.8 \%$ & 9814 & $41.3 \%$ & 26 & $39.4 \%$ & 6121 & $25.8 \%$ & 19 & $28.8 \%$ & 7816 & $32.9 \%$ \\
\hline
\end{tabular}




\section{3 讨论}

\section{1 长江中下游湖泊鱼类多样性变化趋势}

自三峡工程蓄水以来,西洞庭湖鱼类多 样性呈现下降趋势, 尽管在长江流域采取了 一些恢复措施, 但对于鱼类多样性的恢复并 不理想, 本研究记录到三峡大坝运行前后 10 年鱼类物种数由 85 种下降为 66 种. 对比长 江中下游 3 个大型湖泊近几十年的鱼类物种 数变化 ${ }^{[4,6,8,29-33]}$ 也可以看到, 自 $1980 \mathrm{~s}$ 以来, 鱼类物种数一直处于下降趋势之中, 尤其到 了 2000 年之后, 各湖泊鱼类物种数相较于历 史记录下降幅度更加明显(表6). 同时各湖
表 6 长江中下游湖泊鱼类物种数变化

Tab. 6 Variation of fish species number in different lakes of the middle and lower reaches of the Yangtze River

\begin{tabular}{ccccc}
\hline 时间 & 西洞庭湖 & 洞庭湖 & 鄱阳湖 & 太湖 \\
\hline 历史记录 & $111^{[35]}$ & $119^{[36]}$ & $136^{[31]}$ & $103^{[33]}$ \\
$1980 \mathrm{~s}$ & - & $114^{[8]}$ & $117^{[31]}$ & $72^{[33]}$ \\
$1990 \mathrm{~s}$ & - & $104^{[4]}$ & $101^{[31]}$ & $33^{1)[32]}$ \\
2000 年后 & $85^{2)} 、 66^{3)}$ & $69^{[6]}$ & $69^{[30]}$ & $48^{[34]}$ \\
\hline
\end{tabular}

1）仅敞水区;2）本研究 2002-2003 年调查数据;3) 本研究 $2012-2014$ 年调查数据. 泊历史上出现过的多种珍稀濒危物种, 如中华鲟、鳂鳎 (Anguilla japonica)、鲋 ( Macrura reevesi)、鯮 ( Luciobrama macrocephalus) 等,在调查中已很难发现,这与我们的调查也相一致.

在渔获物的组成上,本研究调查结果显示,鱼类个体小型化的趋势依然严峻,优势种中小型个体鱼类比 例进一步上升. 而长江中下游其他湖泊也面临着类似的问题, 张堂林等 ${ }^{[31]} 1997-2000$ 年在鄱阳湖调查显 示,统计的几种主要网具中, 黄滪鱼、鲫等小型鱼类占比约超过 $80 \%$, 毛志刚等 ${ }^{[33]} 2009-2010$ 年在太湖的调 查也显示, 小型鱼类湖鲛 (Coilia ectenes taihuensis) 占到总渔获物比例的 $88.5 \%$.

\section{2 西洞庭湖鱼类群落结构变化驱动力分析}

3.2 .1 大坝对西洞庭湖鱼类群落结构的影响 大坝阻隔会造成鱼类多样性下降 ${ }^{[37]}$. 我国自 $1970 \mathrm{~s}$ 以来,已 建成的水库库容增加了接近一倍 ${ }^{[38]}$, 大坝阻隔不仅阻挠鱼类群落的自由流动, 造成有洄游习性的鱼类种群 数量下降 ${ }^{[5]}$, 而且还会导致流域内原有的水文特征发生改变,对鱼类在下游栖息地的产卵和受食产生影响, 进而降低鱼类多样性 ${ }^{[13,39]}$. 葛洲坝、三峡大坝运行后, 中华鲟、“四大家鱼” 等洄游、半洄游性鱼类种群数量 持续下降 ${ }^{[5,17]}$, 本文调查显示, 西洞庭湖鱼类洄游、半洄游性类群比例从 $5.7 \%$ 进一步下降为 $1.6 \%$. 而近几 年研究也表明, 从西洞庭湖上游澧水、沅水各江段, 到下游东洞庭湖、城陵矶鱼类多样性指数呈现递减的趋 势. 2010-2011 年澧水各江段鱼类多样性指数 $H^{\prime}$ 在 $3.64 \sim 4.60$ 之间, 均匀度指数 $J$ 在 $0.97 \sim 1.07$ 之 间 ${ }^{[40]}$, 而相邻的沅水的多样性指数 $H^{\prime}$ 为 $4.31 \sim 4.93$, 均匀度指数 $J$ 为 $1.10 \sim 1.20^{[41]}$, 其平均值均高于本研 究 2012-2014 年在西洞庭湖调查的鱼类多样性指数 $H^{\prime}(4.14)$ 和均匀度指数 $J(1.00)$.

三峡大坝运行以来, 西洞庭湖水文节律发生明显的变化, 由于汛末蓄水, 西洞庭湖北部流量降低, 高水 位持续时间减少,高位洲滩淹没时间变短 ${ }^{[21]}$. 水文节律的变化造成景观格局改变 ${ }^{[20]}$,并为人工改造湿地提 供了重要条件. 通过对比 2013 年与 1996 年的遥感影像发现, 西洞庭湖湖区杨树林面积增加了 9 倍,芦苇面 积增加了 $30.6 \%$, 水域、草滩、泥滩地等天然湿地面积分别减少了 $46.4 \% 、 49.9 \% 、 39.8 \%$,景观破碎化趋于 严重 ${ }^{[42]}$. 天然湿地丧失可能会对西洞庭湖鱼类 (尤其是产粘性卵的鱼类) 的产卵场和索饵场产生直接影响. 研究证实, 三峡大坝建立以后, 西洞庭湖鲤、鲫产卵场和索饵场数量和面积均在减小 ${ }^{[11]}$. 三峡工程影响下的 水文特征变化可能是造成西洞庭湖鱼类多样性降低 (尤其是产粘性卵鱼类数量比例呈现下降趋势) 的重要 原因,其对于其他鱼类的影响,还需要进一步研究证明.

3.2 .2 过度捕捞对西洞庭湖鱼类群落结构的影响 过度捕捞是威胁鱼类多样性的重要因素 ${ }^{[43]}$. 长江流域自 禁渔以来,部分区域非法捕捞的行为仍然屡禁不止 ${ }^{[4]]}$. 在调查过程中发现,近 10 年来,西洞庭湖禁渔期捕 捞现象依然存在,其渔业作业方式也发生了变化,丝网、迷魂阵等非主动式定置网方式减少, 捕捞效率更高 的电拖网、电笔捕鱼成为当前区域的主要作业方式. 捕捞技术进步在提高渔业捕捞量的同时,也威胁到渔业 资源的可持续发展 ${ }^{[45]}$. 两次调查显示, 中上层鱼类数量比例有显著性差异, 由于各种电鱼捕捞均主要集中 在水域的中上层, 从而对于中上层鱼类造成极大威胁. 作业方式的变化可能是导致西洞庭湖鱼类群落向底 层鱼类集中的主要原因. 
长江流域从上游到下游由于饵料结构变化, 鱼类多样性逐渐升高, 肉食性鱼类也随着可获得的鱼类种 类和生物量逐渐增加而增加 ${ }^{[46]}$. 西洞庭湖位于长江中下游, 饵料丰富, 鱼类多样性高 ${ }^{[4]}$, 然而我们的研究却 显示, 肉食性鱼类尾数所占比例从 2002 年的 $22.0 \%$ 降为 2012 年的 7. $0 \%$ (表 2). Myers 等和 Pauly 等认为, 长期捕捞导致渔获物组成发生极大变化, 高营养级生命周期长的掠食性鱼类逐渐被低营养级的鱼类所代 替 ${ }^{[4748]}$. 王迎宾等和朱晓光等也认为持续的捕捞胁迫将使鱼类往小型化、性早熟方向发展, 短期内休渔期鱼 类资源难以恢复 ${ }^{[49.50]}$. 肉食性鱼类位于食物链顶端, 且往往因个体较大而更容易受到捕捞的影响 ${ }^{\left[{ }^{[} 1\right]}$, 肉食 性鱼类的短缺通过下行效应进一步影响其他鱼类和饵料生物. 西洞庭湖禁渔期较短, 根据相关研究 ${ }^{[47-51]}$ 和 本文的野外调查结果可以推断,长期捕捞胁迫可能导致鱼类向小型、杂食性类群集中.

\section{3 保护对策建议}

目前我国的淡水鱼保护对策主要集中在濒危鱼类和经济鱼类上, 而较少关注其他普通鱼类 ${ }^{[52]}$. 自 1980s 以来, 西洞庭湖鱼类多样性不断恶化, 三峡大坝运行之后, 鱼类群落中的一些特定种群数量正急速下 降, 人类活动对鱼类所造成的影响亟需引起人们的关注. 另一方面, 自然保护区作为保护典型生态系统和生 物多样性的有效措施, 其管理水平和保护水平依然存在较大差异 ${ }^{[53-54]}$. 本研究调查区域主要位于西洞庭湖 国家级保护区, 保护区旗舰物种主要为大型水鸟, 而并未将包括鱼类、湿地植物及其赖以生存的生境在内的 整个生态系统列为同等重要的保护目标, 在监测力度、人员配备以及经费规划中难免厚此薄彼. 然而西洞庭 湖鱼类多样性长期的下降趋势,为保护区生态系统的保护成效敲响了警钟.

在鱼类多样性的恢复过程中, 我们建议: 1) 在整个流域的尺度下合理调度水位, 采取包括水文动态的管 理、洄游性鱼类洄游通道的恢复、栖息地保护与恢复等措施, 减弱三峡大坝运行对中下游湖泊鱼类生物多样 性的影响;2) 加强生态系统综合管理, 提高西洞庭湖及其上下流域和江湖关系管理的联系, 保持湿地生态系 统保护的整体性;3) 加强自然保护区的管理与监测力度, 保护区应该不仅仅是旗舰物种保护区, 而应将鱼类 等所有生态系统组分、生态系统过程作为保护区的保护目标;4) 加强宣传教育、打击非法捕捞;5)进一步加 强江湖关系变化背景下的生态系统响应及其对策研究.

致谢: 感谢西洞庭湖国家级自然保护区工作人员、张雅棉博士、耿雪萌硕士等在野外调查中提供帮助.

\section{4 参考文献}

[ 1 ] 赵志模, 郭依泉. 群落生态学原理与方法. 重庆:科学技术文献出版社重庆分社, 1990.

[2] 冯广朋. 鱼类群落多样性研究的理论与方法. 生态科学, 2008, (6) : 506-514.

[ 3 ] Li J, Dong S, Peng M et al. Effects of damming on the biological integrity of fish assemblages in the middle Lancang-Mekong River basin. Ecological Indicators, 2013, 34:94-102.

[ 4 ] 窦鸿身,姜加虎. 洞庭湖. 合肥: 中国科学技术大学出版社, 2000.

[ 5 ] 易雨君,王兆印. 大坝对长江流域洄游鱼类的影响. 水利水电技术, 2009, (1):29-33.

[6] 茹辉军,刘学勤, 黄向荣等. 大型通江湖泊洞庭湖的鱼类物种多样性及其时空变化. 湖泊科学, 2008,20 (1): 93-99.

[ 7 ] 张 欢, 吴功果, 张 欢等. 东洞庭湖鱼类稳定同位素的季节变化. 水生生物学报, 2013, (4):796-798.

[8] 唐家汉, 钱名全. 洞庭湖的鱼类区系. 淡水渔业, 1979, (10):24-32.

[9] 李杰钦. 洞庭湖鱼类群落生态研究及保育对策 [学位论文]. 长沙: 中南林业科技大学, 2013.

[10］廖伏初,何 望,黄向荣等. 洞庭湖渔业资源现状及其变化. 水生生物学报, 2002, 26(6):623-627.

[11] 李 成. 洞庭湖主要经济鱼类资源调查及其变化规律研究 [学位论文]. 长沙: 湖南农业大学, 2006.

[12] Wang P, Dong S, Lassoie JP. The large dam dilemma. Dordrecht: Springer, 2014:1-23.

[13] Kanehl PD, Lyons J, Nelson JE. Changes in the habitat and fish community of the Milwaukee River, Wisconsin, following removal of the Woolen Mills Dam. North American Journal of Fisheries Management, 1997, 17(2):387-400.

[14] Agostinho AA, Gomes LC, Pelicice FM. Ecology and management of fish resources in reservoirs in Brazil. Maringá: Eduem, 2007.

[15] Wang Z, Yan Z, Xu L et al. Effects of hydrologic regulation on icefish population dynamics, assemblage structure and fishery yield in Lake Nanyi, China. Ecology of Freshwater Fish, 2013, 22 (4) :637-644.

[16] Willis DW, Fish K. Review of water level management on Kansas reservoirs. Kansas Fish and Game Commission, 1982. 
[17] Xie P, Wu J, Huang J et al. Three-Gorges Dam:risk to ancient fish. Science, 2003, 302 (5648) :1149-1151.

[18] Feyrer F, Healey MP. Fish community structure and environmental correlates in the highly altered southern SacramentoSan Joaquin Delta. Environmental Biology of Fishes, 2003, 66(2) :123-132.

[19] Gehrke PC, Gilligan DM, Barwick M. Changes in fish communities of the Shoalhaven River 20 years after construction of Tallowa Dam, Australia. River Research and Applications, 2002, 18(3):265-286.

[20] 黄 群,姜加虎,赖锡军等. 洞庭湖湿地景观格局变化以及三峡工程蓄水对其影响. 长江流域资源与环境, 2013, ( 7 ) :922-927.

[21] 赖锡军,姜加虎, 黄 群. 三峡工程蓄水对洞庭湖水情的影响格局及其作用机制. 湖泊科学, 2012, 24 (2): 178-184.

[22] 黄 群,孙占东,姜加虎. 三峡水库运行对洞庭湖水位影响分析. 湖泊科学, 2011, 23(3):424-428.

[23] 陈宜瑜. 中国动物志: 硬骨鱼纲 - 鲤形目 (中卷). 北京:科学出版社, 2000 .

[24] 伍汉霖,钟俊生. 中国动物志: 硬骨鱼纲 - 鲈形目. 北京:科学出版社, 2008.

[25] 乐佩琦. 中国动物志: 硬骨鱼纲. 鲤形目 (下卷). 北京:科学出版社, 2000 .

[26] 诸新洛,郑葆珊,戴定远. 中国动物志: 硬骨鱼纲・鲇形目. 北京:科学出版社, 1999.

[27] 湖北省水生生物研究所鱼类研究室. 长江鱼类. 北京:科学出版社, 1976.

[28] 钱迎倩, 马克平, 中国科学院等. 生物多样性研究的原理方法. 北京: 中国科学技术出版社, 1994.

[29] 朱松泉. 2002-2003 年太湖鱼类学调查. 湖泊科学, 2004,16(2) :120-124.

[30 ] Huang LL, Wu ZQ, Li JH. Fish fauna, biogeography and conservation of freshwater fish in Poyang Lake Basin, China. Environmental Biology of Fishes, 2013, 96(10/11):1229-1243.

[31] 张堂林,李钟杰. 鄱阳湖鱼类资源及渔业利用. 湖泊科学, 2007, (4) : 434-444.

[32］李圣法,㶓增嘉,邓思明等.太湖敞水区鱼类种间关系现状. 水产学报, 1998, (1):45-49.

[33] 毛志刚,谷孝鸿,曾庆飞等. 太湖鱼类群落结构及多样性. 生态学杂志, 2011, (12) :2836-2842.

[34] 刘恩生,刘正文,陈伟民等. 太湖鱼类产量、组成的变动规律及与环境的关系. 湖泊科学, 2005,17(3):251-255.

[35] 胡军华,胡慧建,何木盈等. 西洞庭湖鱼类物种多样性及其时空变化. 长江流域资源与环境, 2006, (4):434-441.

[36］李杰钦,王德良,丁德明. 洞庭湖鱼类资源研究进展. 安徽农业科学, 2013, (9) :3898-3900.

[37] 王利民,胡慧建, 王 丁. 江湖阻隔对涨渡湖区鱼类资源的生态影响. 长江流域资源与环境, 2005, (3):287-292.

[38］中华人民共和国水利部. 中国水利统计年鉴 2012. 北京:中国水利水电出版社, 2012.

[39] Santucci Jr VJ, Gephard SR, Pescitelli SM. Effects of multiple low-head dams on fish, macroinvertebrates, habitat, and water quality in the Fox River, Illinois. North American Journal of Fisheries Management, 2005, 25(3) :975-992.

[40] 刘良国,杨品红,杨春英等. 湖南境内澧水鱼类资源现状与多样性研究. 长江流域资源与环境, 2013, (9)： $1165-1171$.

[41］刘良国,杨春英,杨品红等. 湖南境内沅水鱼类资源现状与多样性分析. 海洋与湖沼, 2013, (1):148-158.

[42] 刘云珠,史林鹭,朵海瑞等. 人为干扰下西洞庭湖湿地景观格局变化及冬季水鸟的响应. 生物多样性, 2013, 21 (6) :666-676.

[43］曹文宣. 长江鱼类资源的现状与保护对策. 江西水产科技, 2011，(2):1-4.

[44] 陈大庆,段辛斌,刘绍平等. 长江渔业资源变动和管理对策. 水生生物学报, 2002, 26(6) :685-690.

[45] Walsh SJ, Engås A, Ferro R et al. To catch or conserve more fish: the evolution of fishing technology in fisheries science. In: Lang T ed. Fish disease surveys in environmental monitoring: the role of ICES. ICES Marine Science Symposia, 2002 : 202-212.

[46] 丁宝清,刘焕章. 长江流域鱼类食性同资源集团组成特征分析. 四川动物, 2011，(1):31-35.

[47] Myers RA, Worm B. Rapid worldwide depletion of predatory fish communities. Nature, 2003, 423(6937):280-283.

[48] Pauly D, Christensen V, Dalsgaard J et al. Fishing down marine food webs. Science, 1998, 279(5352):860-863.

[49] 王迎宾,郑 基,覃 涛等. 捕捞作用下鱼类资源量变动短期影响的模拟研究. 海洋湖沼通报, 2011, (3):39-45.

[50］朱晓光,房元勇,严力蛟等. 高捕捞强度环境下海洋鱼类生态对策的演变. 科技通报, 2009, (1):51-55.

[51] 纪炜炜, 李圣法,陈雪忠. 鱼类营养级在海洋生态系统研究中的应用. 中国水产科学, 2010, (4) :878-887.

[52] Li J, Huang L, Sato T et al. Distribution pattern, threats and conservation of fish biodiversity in the East Tiaoxi, China. Environmental Biology of Fishes, 2013, 96(4) :519-533.

[53] 杨 军,张明祥,雷光春. 《中国国家级湿地自然保护区保护成效初步评估》中的偏差. 科学通报, 2012, (15): 1367-1371.

[54］郑姚闽,张海英,牛振国等. 中国国家级湿地自然保护区保护成效初步评估. 科学通报, 2012, (4):207-230. 
附表 I 西洞庭湖鱼类各科、目物种数

Appendix I Numbers of fish in each family and order in West Lake Dongting

\begin{tabular}{|c|c|c|c|c|c|}
\hline 名称 & $\begin{array}{c}2002- \\
2003 \text { 年 }\end{array}$ & $\begin{array}{c}2012- \\
2013 \text { 年 }\end{array}$ & 名称 & $\begin{array}{c}2002- \\
2003 \text { 年 }\end{array}$ & $\begin{array}{l}2012- \\
2013 \text { 年 }\end{array}$ \\
\hline 鲱形目( CLUPEIFORMES) & 2 & 1 & 中华鳑鲏( Rhodeus sinensis) & + & + \\
\hline 鳀科( Engraulidae) & 2 & 1 & 高体鳑鲏( Rhodeus ocellatus) & + & \\
\hline 短领鲚(Coilia brachygnathus) & + & + & 鲢 (Hypophthalmichthys molitrix) & + & + \\
\hline 鲚(Coilia ectenes) & + & & 鳙(Aristichthys nobilis) & + & + \\
\hline 鮏形目(SALMONIFORMES) & 3 & 1 & 胭脂鱼科( Catostomidae) & 0 & 1 \\
\hline 银鱼科( Salangidae) & 3 & 1 & 胭脂鱼(Myxocyprinus asiaticus) & & + \\
\hline 大银鱼( Protosalanx hyalocranius) & + & & 鱾科 (Cobitidae) & 6 & 6 \\
\hline 短吻间银鱼 (Hemisalanx brachyrostralis) & + & + & 紫薄鲉 ( Leptobotia taeniops) & + & + \\
\hline 太湖新银鱼(Neosalanx taihuensis) & + & & 大斑花鱾 (Cobitis macrostigma) & + & \\
\hline 鲤形目( CYPRINIFORMES) & 55 & 44 & 中华花鱾 (Cobitis sinensis) & + & + \\
\hline 鲤科( Cyprinidae) & 49 & 37 & 中华沙鳅( Botia superciliaris) & + & + \\
\hline 鲤( Cyprinus carpio) & + & + & 花斑副沙䱊 ( Parabotia fasciata) & + & + \\
\hline 鲫 (Carassius auratus) & + & + & 武昌副沙䱃 ( Parabotia banarescui) & & + \\
\hline 麦穗鱼(Pseudorasbora parva) & + & + & 鲇形目( SILURIFORMES) & 11 & 10 \\
\hline 棒花鱼(Abbottina rivularis) & + & + & 鲿科( Bagridae) & 9 & 6 \\
\hline 华鳈( Sarcocheilichthys sinensis) & + & + & 长吻鮠 (Leiocassis longirostris) & + & \\
\hline 黑鳍鳈( Sarcocheilichthys nigripinnis) & + & + & 粗唇鯔( Leiocassis crassilabris) & + & + \\
\hline 江西鳈( Sarcocheilichthys kiangsiensis) & + & + & 白边拟魭 (Pseudobagrus albomarginatus) & + & + \\
\hline 银鮈 (Squalidus argentatus) & + & + & 切尾拟魭( Pseudobagrus truncatus) & + & \\
\hline 蛇鮈 ( Saurogobio dabryi) & + & + & 乌苏里拟魭 (Pseudobagrus ussuriensis) & + & \\
\hline 光唇蛇鮈 (Saurogobio gymnocheilus) & + & + & 黄颡鱼 (Pelteobagrus fulvidraco) & + & + \\
\hline 吻鮈 (Rhinogobio typus) & + & & 长须黄颡鱼( Pelteobagrus eupogon) & + & + \\
\hline 铜鱼 (Coreius heterodon) & + & & 瓦氏黄颡鱼( Pelteobagrus vachelli) & + & + \\
\hline 花鑑( Hemibarbus maculatus) & + & + & 光泽黄滪鱼( Pelteobagrus nitidus) & + & + \\
\hline 唇鑑 (Hemibarbus labeo $)$ & + & & 鲇科(Siluridae) & 2 & 1 \\
\hline 宜昌鲀鮀 (Gobiobotia filifer) & + & & 鲇( Silurus asotus) & + & + \\
\hline 鳡(Elopichthys bambusa) & + & + & 大口鲇(Silurus meridionalis) & + & \\
\hline 马口鱼 (Opsariichthys bidens) & + & + & 针头鮠科 (Amblycipitidae) & 0 & 2 \\
\hline 赤眼䲡( Squaliobarbus curriculus) & + & + & 白缘酛( Liobagrus marginatus) & & + \\
\hline 鳤(Ochetobius elongatus) & + & & 拟缘酛( Liobagrus marginatoides) & & + \\
\hline 青鱼( Mylopharyngodon piceus) & + & + & 鮡科 (Sisoridae) & 0 & 1 \\
\hline 草鱼(Ctenopharyngodon idellus) & + & + & 中华纹胸鮡( Glyptothorax sinense) & & + \\
\hline 似鮈 (Pseudogobio vaillanti) & + & + & 领针鱼目( BELONIFORMES) & 1 & 1 \\
\hline 伍氏华鳊 (Sinibrama wui) & + & & 鱵科( Hemiramphidae) & 1 & 1 \\
\hline 似鱎( Toxabramis swinhonis) & + & & 间下鱵 (Hemiramphus intermedius) & + & + \\
\hline 鳊 (Parabramis pekinensis) & + & + & 合鰓鱼目( SYNBRANCHIFORMES) & 1 & 1 \\
\hline 团头鲂 (Megalobrama amblycephala) & + & + & 合鳃鱼科( Synbranchidae) & 1 & 1 \\
\hline 三角鲂 (Megalobrama terminalis) & + & + & 黄鳝(Monopterus albus) & + & + \\
\hline 贝氏銫 (Hemiculter bleekeri) & + & + & 鲈形目( PERCIFORMES) & 12 & 8 \\
\hline 銫( Hemiculter leucisculus) & + & + & 鮨科(Serranidae) & 5 & 2 \\
\hline 红鲑原鲌(Cultrichthys erythropterus) & + & + & 长身鲰 (Coreosiniperca roulei) & + & \\
\hline 拟尖头鲌( Culter oxycephaloides) & + & & 鲘 (Siniperca chuatsi) & + & + \\
\hline 尧嘴鲌 (Culter ilishaeformis) & + & + & 斑鳇( Siniperca scherzeri) & + & + \\
\hline 蒙古鲌( Culter mongolicus) & + & + & 大眼鲊 (Siniperca kneri) & + & \\
\hline 达氏鲌( Culter dabryi) & + & + & 花鲈( Lateolabrax japonicus) & + & \\
\hline 银飘鱼( Pseudolaubuca sinensis) & + & + & 塘鳢科( Eleotridae) & 2 & 2 \\
\hline 寡鳞飘鱼 (Pseudolaubuca engraulis) & + & + & 黄黝鱼( Hypseleotris swinhonis) & + & + \\
\hline 黄尾鲖 (Xenocypris davidi) & + & + & 暗色沙塘鳢( Odontobutis obscurus) & + & + \\
\hline 细鳞鲖 (Xenocypris microlepis) & & + & 鰕虎鱼科( Gobiidae) & 2 & 2 \\
\hline 银鲖 (Xenocypris argentea) & + & & 褐栉鰕虎鱼(Ctenogobius brunneus) & + & + \\
\hline 圆吻鲖( Distoechodon tumirostris) & + & & 普栉鰕虎鱼(Ctenogobius giurinus) & + & + \\
\hline 似鳊 (Pseudobrama simoni) & + & + & 斗鱼科( Belontiidae) & 1 & 0 \\
\hline 大鯺鱊( Acheilognathus macropterus) & + & + & 圆尾斗鱼 (Macropodus chinensis) & + & \\
\hline 寡鳞鱊( Acheilognathus hypselonotus) & + & + & 鳢科( Channidae) & 1 & 1 \\
\hline 兴凯鱊( Acheilognathus chankaensis) & + & + & 乌鳢(Channa argus) & + & + \\
\hline 彩副鱊( Paracheilognathus imberbis) & + & & 刺䲝科( Mastacembelidae) & 1 & 1 \\
\hline 彩石鳑鲏( Rhodeus lighti) & + & + & 刺鱾(Mastacembelus aculeatus) & + & + \\
\hline
\end{tabular}

“ + 表示调查到的物种; 数字为各科、目物种数. 